\title{
Lythraceae endémicas del Perú
}

\section{Blanca León ${ }^{1,2}$}

${ }^{1}$ Museo de Historia Natural, Av. Arenales 1256, Aptdo. 14-0434, Lima 14, Perú

2 Plant Resources Center, University of Texas at Austin, Austin TX 78712 EE.UU.

blanca.leon@mail.utexas.edu

\section{Resumen}

La familia Lythraceae es reconocida en el Perú por presentar 10 géneros y 30 especies (Brako \& Zarucchi, 1993; Ulloa Ulloa et al., 2004), la mayoría hierbas y arbustos. En este trabajo reconocemos una especie endémica en el género Cuphea. Esta especie endémica ocupa la región de los Bosques Muy Húmedos Montanos, entre los 2400 y 3000 m de altitud. No se encuentra representada en el Sistema Nacional de Áreas Naturales Protegidas por el Estado.

Palabras claves: Lythraceae, Cuphea, Perú, endemismo, plantas endémicas.

\section{Abstract}

The Lythraceae are represented in Peru by 10 genera and 30 species (Brako \& Zarucchi, 1993; Ulloa Ulloa et al., 2004), mostly herbs and shrubs. Here we recognize one endemic taxon in the genus Cuphea. This endemic has been found in areas of the Very Humid Montane Forest region, between 2400 and 3000 m elevation. It has not yet been registered within the Peruvian protected areas system.

Keywords: Lythraceae, Cuphea, Peru, endemism, endemic plants.

\section{Cuphea vargasii J.F. Macbr.}

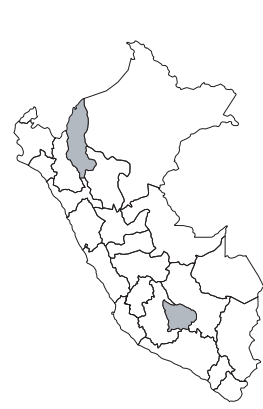

\section{DD}

Publicación: Field Mus. Nat. Hist., Bot. Ser. 13(4/1): 215. 1941

Colección tipo: H.E. Stork et al. 10589

Herbarios: F, UC.

Nombre común: Desconocido.

Registro departamental: AM, AP.

Regiones Ecológicas: BMHM; 2400$3000 \mathrm{~m}$.

SINANPE: Sin registro.

Herbarios peruanos: CPUN (1).

Observaciones: Subarbusto, conocido de ambientes pantanosos, de localidades dispersas, en las cuencas del Apurímac y del Marañón. Poco se sabe de la situación de sus poblaciones. 